\title{
Interspecific Hybrid of Xeric Shepherdia rotundifolia and Riparian Shepherdia argentea: Description, and Traits Suitable for Low-water Urban Landscapes
}

\author{
Chalita Sriladda ${ }^{1}$ \\ Department of Plants, Soils, and Climate, Utah State University, 4820 Old \\ Main Hill, Logan, UT 84322
}

Heidi A. Kratsch

University of Nevada Cooperative Extension, 4955 Energy Way, Reno, NV 89502

\author{
Steven R. Larson and Thomas A. Monaco \\ USDA-ARS, Forage and Range Research Laboratory, Utah State University, \\ Logan, UT 84322
}

FenAnn Shen

Vice President Research Office, Utah State University, Logan, UT 84322

\author{
Roger K. Kjelgren \\ Department of Plants, Soils, and Climate, Utah State University, 4820 Old \\ Main Hill, Logan, UT 84322
}

Additional index words. AFLP, SEM, ecophysiology, roundleaf buffaloberry, silver buffaloberry

Abstract. Shepherdia rotundifolia Parry (roundleaf buffaloberry), a shrub endemic to the U.S. Colorado Plateau high desert, has aesthetic and drought tolerance qualities desirable for low-water urban landscapes. However, slow growth and too often fatal sensitivity to wet or disturbed soil stymies nursery production and urban landscape use. The goal of this study was to create an interspecific hybrid between the evergreen-xeric $S$. rotundifolia and its widely adapted, fast-growing, deciduous relative Shepherdia argentea (silver buffaloberry) distributed in western North America riparian habitats. Genetics and leaf morphology of the resulting $S$. argentea $\times S$. rotundifolia hybrid are described and compared with the parents, as well as hybrid gas exchange as a reasonable proxy for growth rate and potential tolerance of poor soil. Hybrid genotypes were heterogenous, but contained an intermediate and equal contribution of alleles from genetically heterogenous parent populations. Leaf morphology traits were also intermediate between both parents. Aesthetic leaf qualities (silver-blue color and revolute margins) sought from $S$. rotundifolia were conserved in all offspring. However, gas exchange responses varied widely between the two surviving hybrids. Both hybrids showed greater tolerance of wet, fertile substrate — and promise for use in low-water landscapes - than $S$. rotundifolia. However, one hybrid conserved faster growth, and by inference possibly greater tolerance of wet or disturbed soil, from $S$. argentea, while the opposite was observed in the second hybrid. Following botanical nomenclature, we named this hybrid Shepherdia $\times$ utahensis.

Across the arid to semiarid U.S. Intermountain West (IMW) human populations increase but water supplies do not. Combined with cyclic drought, water shortages in IMW

Received for publication 20 Feb. 2014. Accepted for publication 20 May 2016.

We thank Linnea Johnson for help in genetic lab works and Graham Hunter for help in field data collection. We thank the Utah Agricultural Experiment Station for financial support (Utah Agricultural Experiment Station paper 8707).

${ }^{1}$ Corresponding author. E-mail: sriladda@gmail.com. urban areas challenge managers to conserve water in irrigated urban landscapes. Irrigated cool-season turfgrass landscapes in particular require large amounts of water (Kjelgren et al., 2000). Low water-use landscaping (LWL) is a key tool in reducing water use in urban landscapes (Kjelgren et al., 2009; St. Hilaire et al., 2008) in the arid to semiarid IMW. Native IMW drought-adapted species are needed for LWL to reduce water consumption, provide a native aesthetic, and enhance urban biodiversity (Meyer et al., 2009).

Even though native drought-adapted species can reduce water use and enhance biodiversity in LWL, establishment under environmental conditions characteristic of urban landscapes can be difficult (Mee et al., 2003). Urban soil is often disturbed and poorly drained, traits typically at odds with native habitat soils of IMW drought-adapted species (Edmondson et al., 2011). In the arid IMW, several drought-adapted native species have been identified for potential use in LWL, but are sensitive to wet soils and irrigation (Meyer et al., 2009). Genetic improvement may enable domestication and use of these native species in LWL.

The genus Shepherdia (Elaeagnaceae) contains $S$. rotundifolia Parry, common name roundleaf buffaloberry, a shrub endemic to the IMW Colorado Plateau in southeast Utah and northern Arizona (USDA, 2012). Shepherdia rotundifolia is dioecious (Nelson, 1935), naturally occurring on very well drained, arid hillside slopes and canyons (Sriladda et al., 2014). This species has desirable aesthetic and practical traits, including extreme drought tolerance and evergreen, revolute, silver-blue (glaucous) foliage forming multiple clusters of attractive rosettes in a nearly perfect hemispherical crown form (Sriladda et al., 2014). However, anecdotally S. rotundifolia is very slow growing and sensitive to overwatering and disturbed soils. Therefore, the species is difficult to grow in either nursery or urban landscape settings. By contrast, $S$. argentea (Pursh) Nutt. (silver buffaloberry) is a closely related dioecious, deciduous, and fast-growing shrub found throughout much of western North America. Shepherdia argentea tolerates a wide range of conditions from dry to wet soils (Chen et al., 2009; Mee et al., 2003), but is limited to riparian areas in the IMW (Richer et al., 2003). However, S. argentea is thorny with an indistinct, rangy growth habit less aesthetically desirable when compared with $S$. rotundifolia (Mee et al., 2003).

Interspecific hybridization plays an important role in plant adaptive evolution, and the process often results in phenotypic novelty in the hybrid, both morphologically and physiologically (Scascitelli et al., 2010; Soltis and Soltis, 2009; Stelkens et al., 2009). There is no documented evidence of a natural hybrid between $S$. rotundifolia and $S$. argentea, possibly because contrasting habitats creating geographical barriers to pollination. A hybrid between $S$. rotundifolia and $S$. argentea may offer the potential of a new taxon suitable for LWL in the IMW: aesthetic and extreme drought tolerance qualities of $S$. rotundifolia but greater tolerance of wet, disturbed soils and faster growth of $S$. argentea. This study describes an interspecific hybrid between the two species in terms of genetics and leaf morphology comparison with its parents. We also compare with its parents hybrid leaf traits desirable for urban landscapes, and gas exchange responses as a reasonable proxy for growth potential and soil tolerances.

\section{Materials and Methods}

Hybridization. Male and female populations of both species were located near the central Utah town of Torrey. We identified 
female populations of $S$. rotundifolia and $S$. argentea in native habitats where they were in close proximity. We hand cross-pollinated five female $S$. argenetea plants in a population adjacent to the Fremont River (38.3 N, 111.4 W). Each female parent was bagged with five pollination bags per plant including a control bag with no pollination. We bagged (11 Apr. 2008) before flowers opened to prevent unexpected pollination from male plants. Five female $S$. rotundifolia plants from a population located on a rocky hillside of Boulder Mountain (38.2 N, 111.4 W) were similarly bagged on the same day with female $S$. argentea.

On 30 Apr. 2008, when flowers of both female $S$. argentea and $S$. rotundifolia were open, fresh pollen was collected from male plants of both species from a population located closest to the bagged female plants for reciprocal crosses. Pollen from $S$. argentea used to pollinate the female $S$. rotundifolia was collected from male plants at the same location with bagged female $S$. argentea. Since male plants were absent at the $S$. rotundifolia female parent site, we collected pollen from male plants at a different $S$. rotundifolia population located adjacent to, but not in Capital Reef National Park $(38.3 \mathrm{~N}, 111.3 \mathrm{~W})$ to pollinate with the female $S$. argentea.

On 29 May 2008, we collected all pollination bags from the female populations of $S$. rotundifolia and $S$. argentea. However, only one pollination bag collected from a bagged female $S$. argentea contained seeds. No seeds were found in any pollination bag collected from female $S$. rotundifolia. Poor seed yield from the crosses suggest factors that limit hybridization other than distances between the different habitats. Seeds collected from female $S$. argentea were subjected to coldstratification and germination as described by Beddes and Kratsch (2009). One week after planting, we observed a total of five germinated seeds. Seedlings were transplanted to a well-drained, mostly inorganic (pumice) growing substrate designed for IMW native plants (Beddes and Kratsch, 2009). Seedlings were watered every other day. In Winter 2008 , hybrid seedlings were placed in a walkin cooler $\left(3{ }^{\circ} \mathrm{C}\right)$ to prevent outdoor freezing damage. In addition to the interspecific hybrid seeds, seeds of $S$. rotundifolia and $S$. argentea were collected from both female parent populations, geminated, and grown under the same conditions with the hybrid for future comparisons.

In Summer 2009, hybrid and parent plants were transplanted into no. 3 (12 L) containers filled with the same native plant substrate. These plants were grown in a pot-in-pot system in a common garden setting at the Utah State University Greenville Research Farm (Logan, UT). Plants were irrigated to field capacity once per week. Three out of five hybrid plants survived until midsummer and were used for the morphological studies, but a third hybrid died on Fall 2010, so its data were not included in the 2010 physiological studies.

Genetics. Leaf samples (two to three leaves per plant) were collected from the field populations of $S$. rotundifolia $(\mathrm{n}=5)$ and $S$. argentea $(n=6)$, and from the five germinated hybrid plants. Leaf samples were dried in 28-200 mesh silica gel (Fisher Scientific, Pittsburgh, PA). DNA was extracted with the Dneasy 96 Plant Kit (QAIGEN, Valencia, CA). Amplified fragment length polymorphisms (AFLPs) were assayed to fingerprint the genomes of the three taxa, as described by Vos et al. (1995) with described modifications. The DNA samples were pre-amplified with EcoRI +1 /MseI +1 using A/C selective nucleotides. Selective amplification primers consisted of five EcoRI $+3 /$ MseI +3 primer combinations using AAC/CAA, AAG/CAG, ACC/CAT, ACG/CTA, AGG/CTA, AGA/ CCC selective nucleotides. The EcoRI selective amplification primers included a fluorescent 6-carboxy fluorescein label on $5^{\prime}$ nucleotides.

Selective amplification products were combined with GS600 LIZ internal lane size standard and were fractionated using an $\mathrm{ABI}$ 3730 instrument with $50-\mathrm{cm}$ capillaries and sized between 50 and 600 bp with Genescan software (Applied Biosystems, Foster City, CA). Although DNA molecules vary in length by increments of $1 \mathrm{bp}$, the relative mobility of bands is also affected by sequence composition. Thus, nonhomologous bands of the same length may not have the same relative mobility. Genescan trace files for each individual were analyzed visually for the presence or absence of DNA bands in bins that were $0.3 \mathrm{bp}$ or more apart using Genographer software (available for free download at http://hordeum. oscs.montana.edu/genographer/ or directly from the author, Tom Blake, at blake@ hordeum.oscs.montana.edu).

Bayesian clustering of five individual plants per taxa without a priori assignment of individuals to hierarchical groups was used to determine genetic structure and test for possible admixture between taxa, which might otherwise confound phylogenetic analysis, using Structure v2.1 (Pritchard et al., 2000). Three analyses were used of each model with 100,000 iterations and 10,000 burn-in or 200,000 iterations and 20,000 burn-in with the dominantallele, admixture model of Structure v2.2 (Falush et al., 2007; Pritchard et al., 2000). A principal coordinates analysis (PCA) based on pairwise comparisons of similarity coefficients (Dice, 1945) from AFLP band matching patterns was developed using the DCENTER and EIGEN procedures of NTSYS-pc, version 2.0 (Rohlf, 1993).

Morphology. Morphological characteristics of the hybrids compared with the parents were described on the basis of leaf traits. At the time of measurement, hybrid plants were not large enough to make any assessment of crown morphology. Leaf morphological measurements on three leaves per plant included petiole length, leaf length and width, and leaf length/leaf width ratio on the three 2-year-old plants of the hybrid and $S$. argentea. These same measurements were made on three $S$. rotundifolia plants grown from cuttings. Additionally, fine-scale morphological differences were compared through scanning electron microscopic (SEM) images. Three leaf punches per plant were collected from three plants of each species and the hybrid, and directly fixed in formalin-aceto-alcohol solution in the field. The fixed leaf tissue was subjected to critical point drying using Samdri-PVT-3D (Tousimis, Rockville, MD). Microscopic images of leaf structure were collected from the SEM at the Nanoelectronics laboratory (Utah State University, Logan, UT). Characteristics measured included average leaf thickness and leaf trichome structures. In addition, hybrid plants were qualitatively observed for deciduous vs. evergreen leaf habit over two winters, 2010-11 and 2011-12.

Physiology. We collected physiological snapshots of gas exchange differences among the three taxa. Shepherdia rotundifolia is extremely slow growing compared with $S$. argentea and, initially, the interspecific hybrid plants. Therefore, for the purpose of morphological and physiological studies, we used plants more rapidly grown from rooted cuttings taken from the bagged female population of S. rotundifolia. In April 2008, stem bases of $S$. rotundifolia cuttings from plants growing in their natural habitats were rooted and held on a propagation bench for 12 weeks under shadecloth (50\% shade) and irrigated using intermittent mist. Rooting was $100 \%$, and rooted plants were then handled the same as the seed-grown taxa.

Physiological responses of the two surviving hybrid plants were compared with three individuals of each parent species under well-watered, common-garden growing conditions of Summer 2010. We measured stomatal conductance $\left(g_{\mathrm{S}}\right)$ using a leaf porometer (SC-1 Porometer; Decagon Device, Pullman, WA). Before each $g_{\mathrm{S}}$ measurement day the porometer was calibrated to a manufacturer vapor plate with different-sized holes overlying filter paper wetted with distilled water. The porometer was again calibrated after measurement to track potential drift. Diurnal $g_{\mathrm{S}}$ was measured on 28 June 2010 on three fully expanded mature, sunlit leaves for each

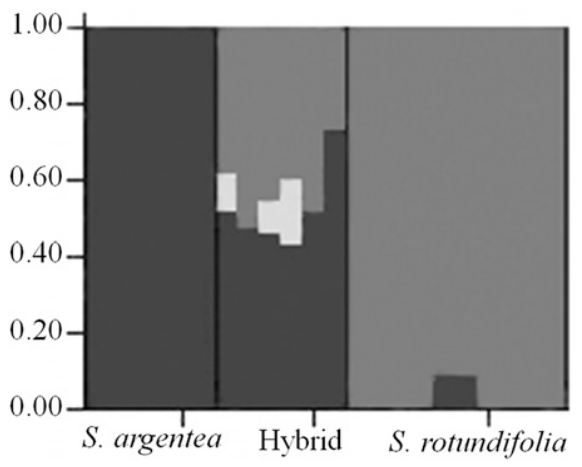

Fig. 1. Inferred population structure of Shepherdia rotundifolia, Shepherdia argentea, and hybrid $S$. rotundifolia $\times$ argentea AFLP genotypes when testing a three population model $(\mathrm{K}=3)$ in Bayesian cluster analysis; the two interior vertical black lines separate individuals of the two parents from the hybrid population $(n=5)$. 


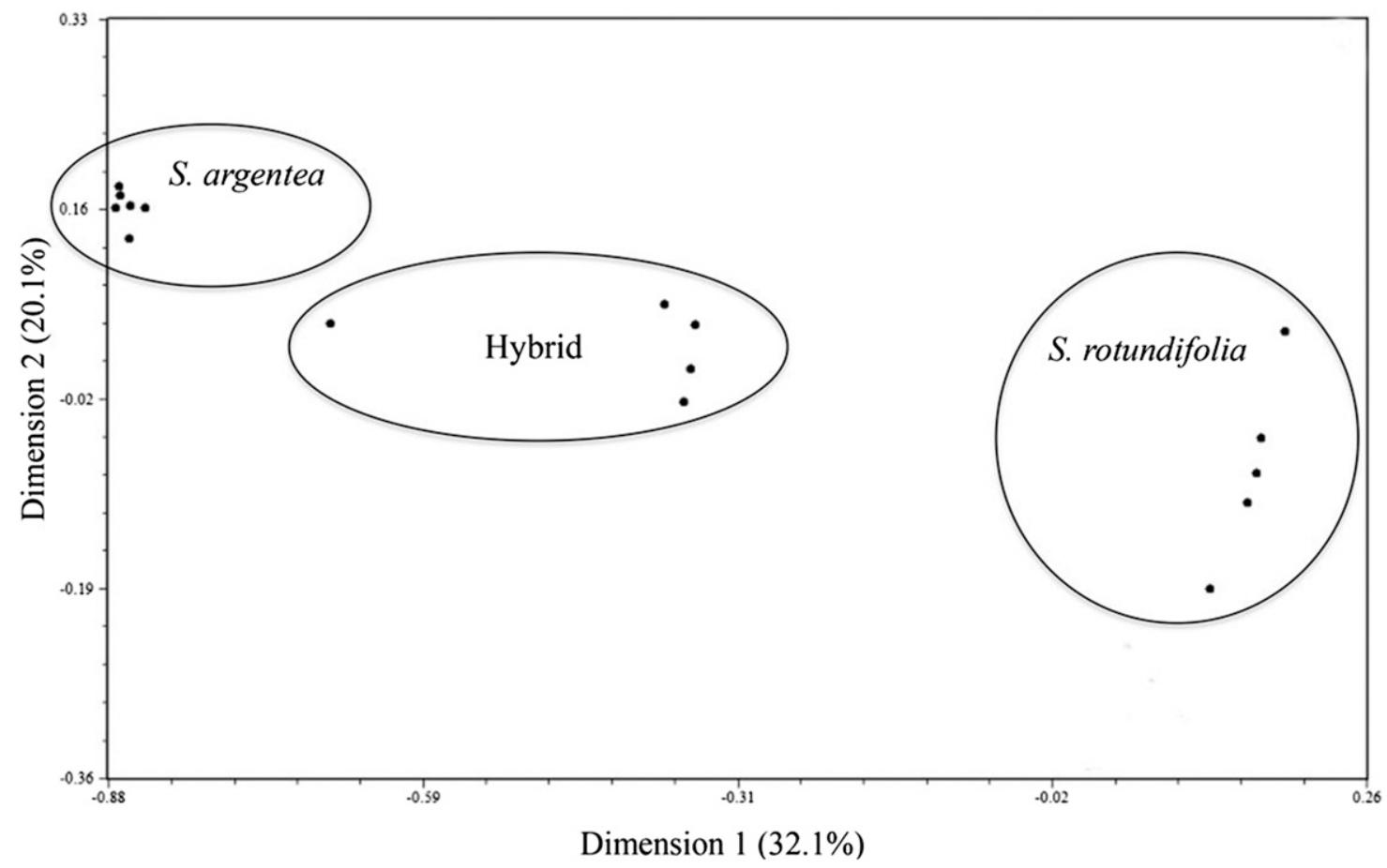

Fig. 2. Principal coordinates analysis of Shepherdia argentea, Shepherdia rotundifolia, and interspecific hybrid individual plants based on pairwise comparisons of AFLP genotypes. Percentages after dimensions 1 and 2 indicate how well the total AFLP variation among individual plants was explained by each dimension

individual plant every hour from 8:00 AM to 5:00 PM on a sunny day. Prior $g_{\mathrm{S}}$ measurements of $S$. rotundifolia at the male parent location near Torrey showed that the range of variation and absolute values of $g_{\mathrm{S}}$ were very similar to clonal plants measured in the common garden (data not shown).

In addition to diurnal $g_{\mathrm{S}}$ measurement, midday $g_{\mathrm{S}}$ was measured weekly from 5 through 26 July 2010, along with midday net photosynthetic rate $\left(\mathrm{P}_{\mathrm{n}}\right)$. $g_{\mathrm{S}}$ and $\mathrm{P}_{\mathrm{n}}$ measurements were conducted using a portable photosynthesis system (LI-6400; LI-COR Corp., Lincoln, NE) also under full sun conditions. Midday $\mathrm{Pn}$ and $g_{\mathrm{s}}$ were measured between 11:00 AM and 1:00 PM when peak solar radiation intensity of solar radiation was relatively constant, and when stomata were most active. Finally, we conducted a light response curve on one leaf each of all three taxa on 20 July 2010 using the LI-6400-02B light source attached to the cuvette. Leaf chamber environment during measurements of all plants was maintained at $400 \mu \mathrm{mol} \cdot \mathrm{mol}^{-1}$ $\mathrm{CO}_{2}$ concentration, $500 \mu \mathrm{mol} \cdot \mathrm{s}^{-1}$ airflow (Monaco et al., 2005), and $24{ }^{\circ} \mathrm{C}$ block temperature (varying $1-2{ }^{\circ} \mathrm{C}$ depending on ambient temperature during measurement).

\section{Results and Discussion}

Genetics. Offspring plants were definitively $S$. rotundifolia $\times S$. argentea hybrids, genetically intermediate between the two parents (Figs. 1 and 2). Shepherdia parents were AFLP genotypes from natural populations of $S$. rotundifolia and $S$. argentea, genetically heterogeneous and distinct from each other. Moreover, plants grown from

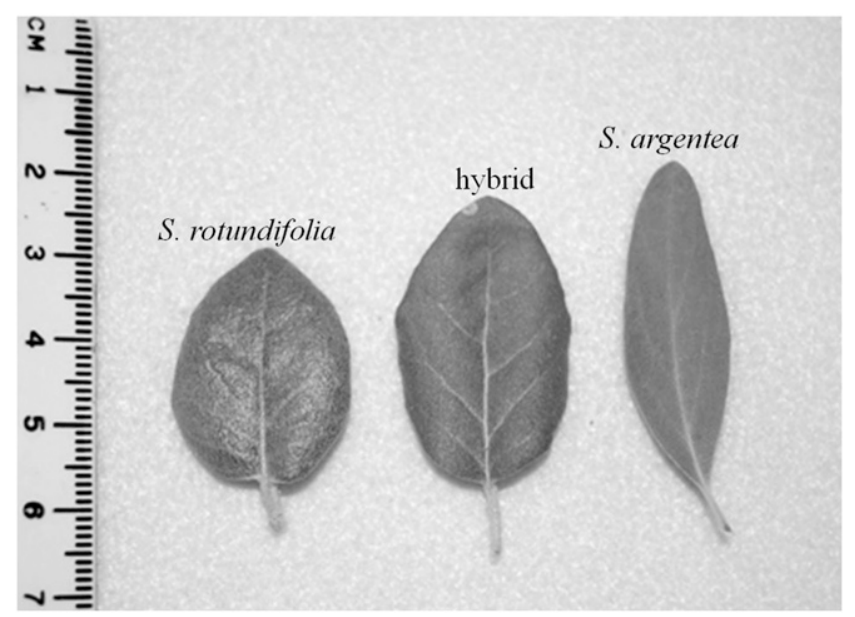

Fig. 3. A leaf of the interspecific hybrid (Shepherdia rotundifolia $\times$ argentea) compared with its parents.

Table 1. Leaf morphological characteristics of Shepherdia rotundifolia, Shepherdia argentea, and the interspecific hybrid S. rotundifolia $\times$ argentea $(\mathrm{n}=3+\mathrm{sD})$.

\begin{tabular}{lccr}
\hline & \multicolumn{3}{c}{ Species } \\
\cline { 2 - 4 } Morphology & S. rotundifolia & S. rotundifolia $\times$ argentea & S. argentea \\
\hline Petiole length $(\mathrm{mm})$ & $5.3 \pm 0.0$ & $10.5 \pm 1.2$ & $7.0 \pm 0.0$ \\
Leaf length $(\mathrm{mm})$ & $24.0 \pm 0.7$ & $39.3 \pm 3.3$ & $42.5 \pm 0.5$ \\
Leaf width $(\mathrm{mm})$ & $23.3 \pm 0.3$ & $24.5 \pm 1.2$ & $12.7 \pm 0.3$ \\
Leaf length/width & $1.0 \pm 0.0$ & $1.6 \pm 0.1$ & $3.4 \pm 0.1$ \\
\hline
\end{tabular}

seeds collected from the pollination bag on the $S$. argentea female parent were also genetically heterogeneous and significantly different from both parents. Bayesian cluster analysis of AFLP genotypes of $S$. rotundifolia, S. argentea, and cross-bred progeny indicated that the hybrids contain an equal contribution of alleles from each parent species (Fig. 1). Therefore, these genetic data support five plants grown from seeds collected from the pollination bag on the $S$. argentea female parent are interspecific hybrids between female $S$. argentea and male $S$. rotundifolia parents. Principal coordinates 
analysis of the AFLP genotypes clearly separated $S$. rotundifolia and $S$. argentea in the first dimension, with the five hybrids located in the middle (Fig. 2). The second dimensions separated individuals within a population, indicating that genetic heterogeneity within the hybrid individuals resembled that of both parents. The first and second dimensions from this principal coordinate analysis explained $32.1 \%$ and $20.1 \%$ of the total AFLP variation among individual plants, respectively.

Morphology. Overall, leaves of the interspecific hybrid $S$. rotundifolia $\times S$. argentea appeared to have conserved desirable leaf shape characteristics of $S$. rotundifolia (Fig. 3). Leaf shape of $S$. rotundifolia is revolute-oval with about equal leaf length and leaf width (Table 1). By contrast, leaf shape of $S$. argentea is entire-lanceolate. Even though leaf length of the hybrid was more similar to $S$. argentea when compared with $S$. rotundifolia, its relatively wide leaf translates to a leaf length/width ratio more similar to $S$. rotundifolia. Petiole length of the hybrid was greater than that of either of the parents. As the offspring of evergreen ( $S$. rotundifolia) and deciduous (S. argentea) species, hybrid leaf habit was ostensibly intermediate between the two parents. Initially, during the growing season, hybrid early-emergence leaves appeared to be closer in leaf habit to $S$. argentea, flatter and less glaucous, and were shed during the winters of 2010-11 and 2011-12. However, hybrid leaves emerging later in the season during peak midsummer heat were closer to $S$. rotundifolia in morphology, being more revolute, glaucous, and did not abscise during winter, creating a semievergreen winter habit.

Leaf thickness of the hybrid was also intermediate $(\approx 370 \mu \mathrm{m})$ to the parents: $S$. rotundifolia $(\approx 754 \mu \mathrm{m})$ and $S$. argentea $(\approx 251 \mu \mathrm{m})$ (Fig. 4A-C). Leaf trichomes on the adaxial (upper) side of the male $S$. rotundifolia parent were peltate, whereas trichomes on the abaxial (lower) side were stellate (Fig. 4A). Leaf trichomes on both surfaces of the female parent, $S$. argentea, were peltate (Fig. 4C). Female parent leaf structure appeared to dominate leaf trichome structure in the hybrid, which had peltate trichomes on both leaf surfaces (Fig. 4B). However, the abaxial trichomes of the hybrid were relatively thicker than those of $S$. argentea. In addition, we observed tall scales emerging from the peltate trichome coverage of the adaxial surface of the hybrid that were not observed in either parent. Emergent phenotypic features generated in interspecific hybrids, such as the tall trichomes observed here, may be rare, but have potential to create a new lineage and lead to evolutionary divergence (Johnston et al., 2004).

Intermediate morphological characteristics of the hybrid (Table 1; Fig. 3) are similar to findings of Kuhlman et al. (2008) in the interspecific hybrid of Sorghum bicolor xmacrospermum and Sun et al. (2010) in the interspecific hybrid of Chrysanthemum grandiflorum $\times$ indicum. However, interspecific
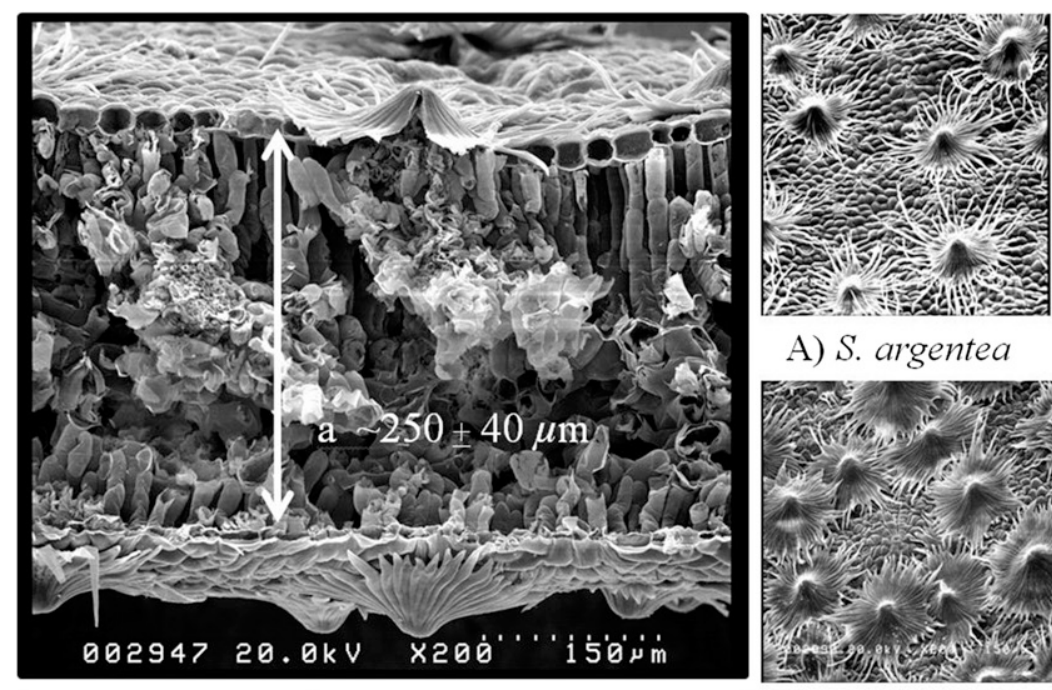

A) S. argentea
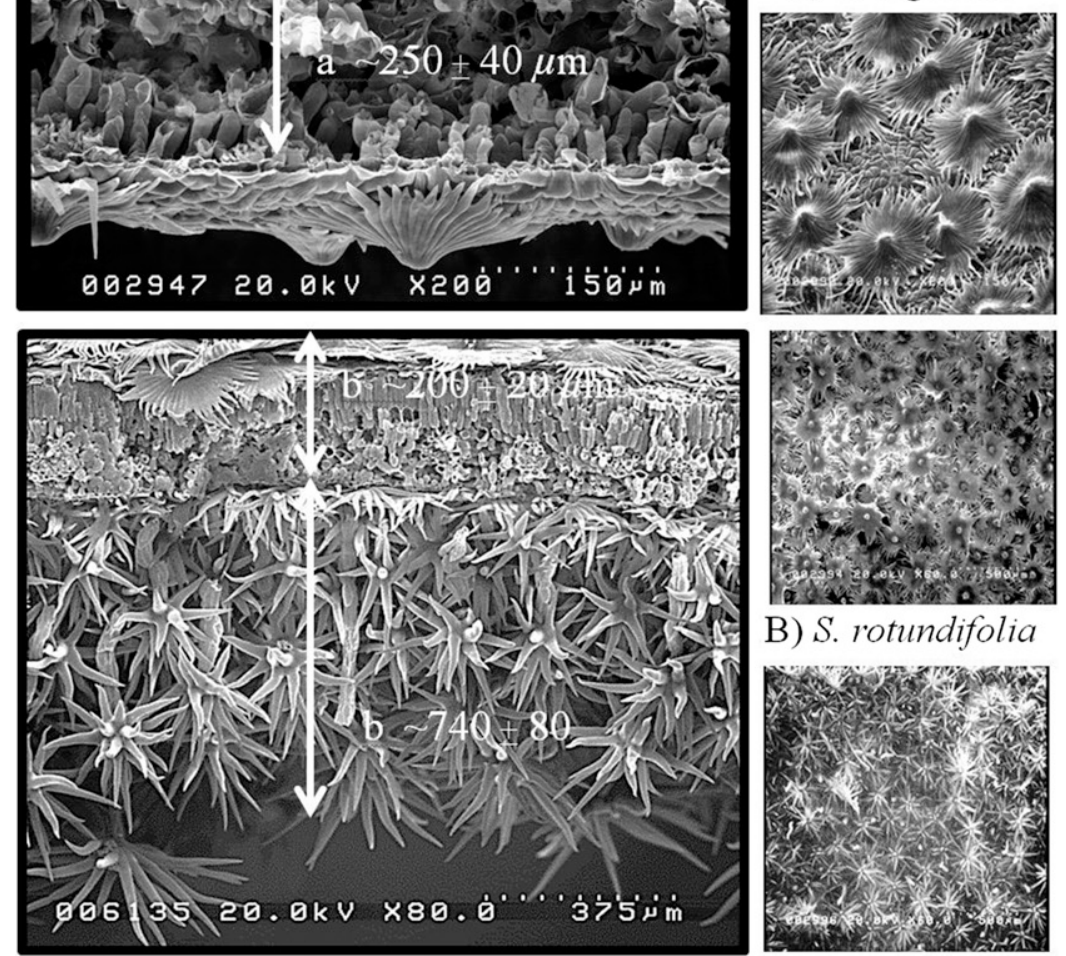

B) S. rotundifolia
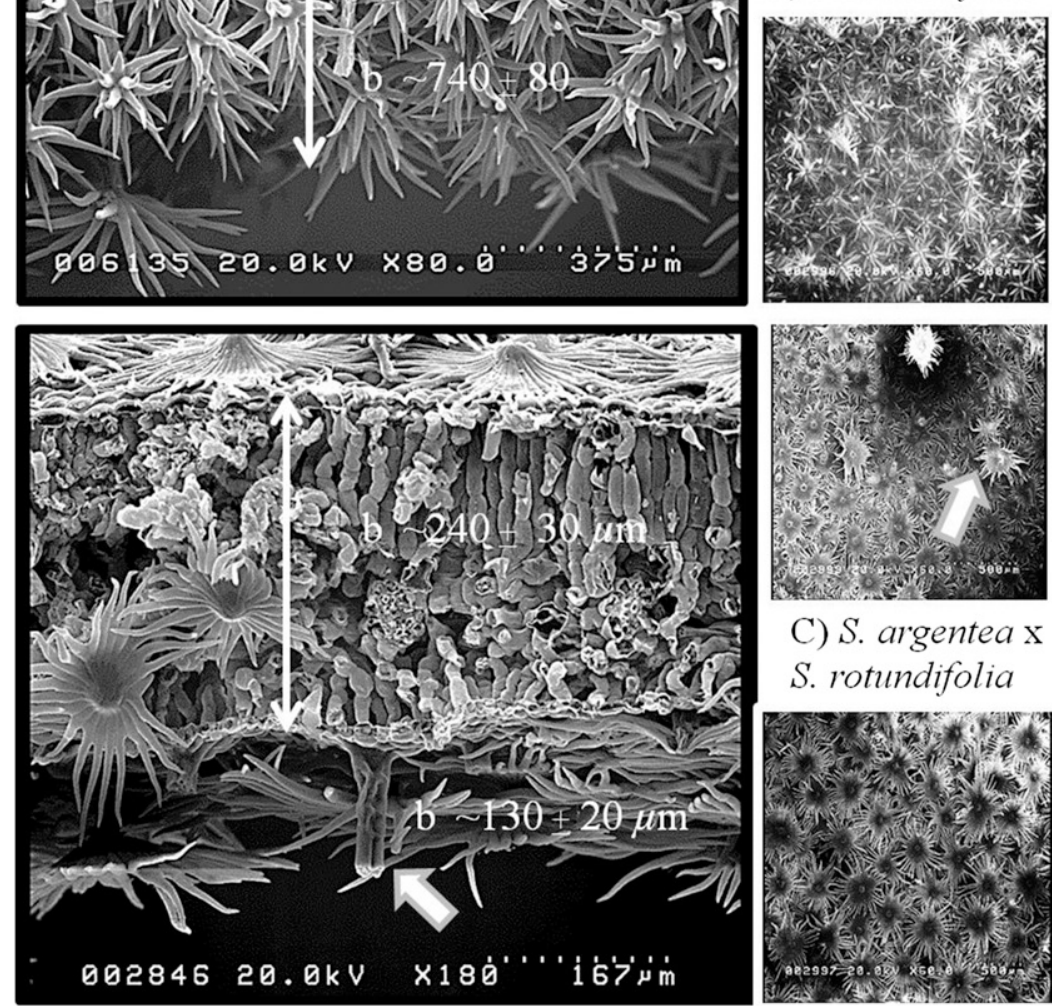

C) $S$. argentea $\mathrm{x}$

S. rotundifolia

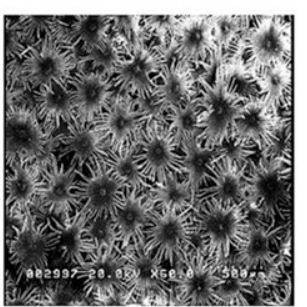

Fig. 4. Scanning electron microscopic images of representative adaxial (top) and abaxial (bottom) leaves: (A) Shepherdia argentea, (B) Shepheridia rotundifolia, and (C) hybrid S. rotundifolia $\times$ argentea. Arrows indicate emergent trichomes not found in either parent.

hybrid morphological traits can be significantly different from one or both parents (Jakesova et al., 2011; Jun et al., 2009). Morphological variation in a hybrid can result in emergent phenotypic novelty (Scascitelli et al., 2010; Soltis and Soltis, 2009; Stelkens et al., 2009), such as the interspecific hybrid between orchid
Ophrys arachnitiformis and Ophrys lupercalis producing more and different compounds in their floral odor, triggering fewer inspecting flights, and contacts by male bees than those of the parental orchid species (Vereecken et al., 2010). Similarly, leaf orientation related to petiole length as an emergent property of the 
hybrid may allow greater flexibility in light absorption to reduce self-shading and increase photosynthetic rate than either parent (Yamada et al., 2000).

Stellate trichomes on the abaxial surface of $S$. rotundifolia were densely packed, resulting in thicker leaves when compared with $S$. argentea and the hybrid (Fig. 4A-C). The dense layer of abaxial trichomes would contribute to a thicker atmospheric boundary layer and greater resistance to water vapor movement and reduce transpiration, an advantage in S. rotundifolia's hot and dry native habitat (Press, 1999). The peltate structure on all three taxa is also advantageous in reflecting solar radiation (Karabourniotis et al., 1993), but may not limit transpiration to the same extent as the stellate trichomes. Lack of abaxial stellate trichomes in $S$. argentea may reflect its IMW riparian habitats (Richer et al., 2003), where a thicker boundary layer that lowers transpiration, and possibly photosynthesis would not be an advantage. Peltate trichomes in the offspring similar to that of $S$. argentea, but clearly thicker, may imply a similar adaptation to wet soil conditions between the hybrid and $S$. argentea.

Physiology. A snapshot assessment of physiological differences in comparison with the parents indicated that gas exchange among the two surviving hybrid plants was more variable than in genetics and morphology. $g_{\mathrm{S}}$ measured in the common garden study were similar in magnitude to dawn-to-dusk measurements collected in situ on five plants of each species (data not shown), suggesting the common garden measurement were representatives of species differences. In the common garden study under full sun, $g_{\mathrm{s}}$ of the fast-growing $S$. argentea was greater than slow-growing $S$. rotundifolia from 08:00 AM until around 12:00-01:00 PM, when $g_{\mathrm{S}}$ of both species was not different (Fig. 5). Hybrid gas exchange with unlimited water was not intermediate between the riparian and xeric parents. Over the day, the difference in $g_{\mathrm{S}}$ between hybrids (1) and (2) was consistently greater than the variance among the individual parent plants of each species (Fig. 5).

Differences in midday $g_{\mathrm{S}}$ (measured with an infrared gas analyzer system rather than porometer) between $S$. argentea and $S$. rotundifolia were minimal when measured under full sun once a week over a 4 -week period (Fig. 6A), confirming the pattern of $g_{S}$ over the course of day seen in Fig. 5. However, $S$. argentea displayed more aggressive carbon uptake strategies (Fig. 6B) characteristic of species adapted to a regularly available water supply (Franks et al., 2007). Conversely, consistently lower $\mathrm{P}_{\mathrm{n}}$ in $S$. rotundifolia, despite nonlimiting root-zone water, meant lower carbon uptake and water use efficiency. Gas exchange variation between the two hybrid plants was again greater than between the two parents. Over the same period, midday physiological response $\left(\mathrm{P}_{\mathrm{n}}\right.$ and $\left.g_{\mathrm{S}}\right)$ of hybrid (1) was greater than the other hybrid (2) and either parent (Fig. 6A-B). Toward the end of the study period, hybrid (2) exhibited even lower $\mathrm{P}_{\mathrm{n}}$ and $g_{\mathrm{S}}$ than those of either parent.

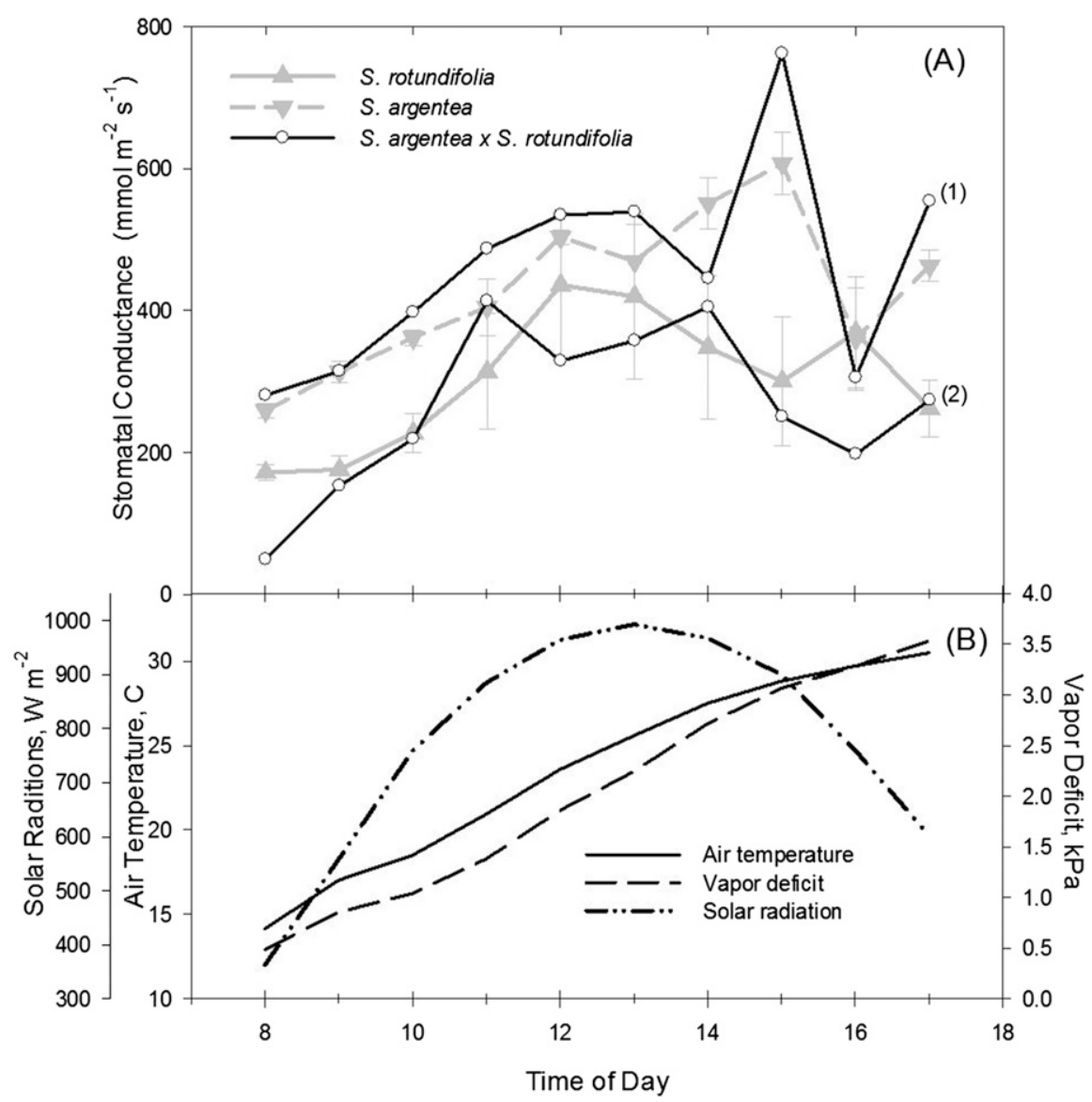

Fig. 5. (A) Dawn-to-dusk stomatal conductance $\left(g_{\mathrm{S}}\right)$ of Shepherdia rotundifolia, Shepherdia argentea, and the interspecific hybrid, S. rotundifolia $\times$ argentea. (B) Weather (air temperature, vapor deficit, and incoming solar radiation) during the day of measurement. Lines labeled with (1) and (2) indicate responses of the single hybrid plants, and S. rotundifolia and S. argentea responses include SD $(\mathrm{n}=3)$.

Similarly, the light response of the two parents showed the same inflection point at roughly $50 \%$ of full sun, but again $S$. argentea was greater than $S$. rotundifolia, in this case $\approx 20 \%$ (Fig. 7). Greater photosynthetic rate of hybrid (1) was amplified in the light response curve, nearly 3 -fold greater than the other three taxa. Schwinning et al. (2005) reported similar unresponsiveness to supplemental water in other desert species that are essentially dormant during summer drought. Extreme xeric species such as $S$. rotundifolia are specialists: programmed to not respond to optimal water conditions during summer heat and drought (Newingham et al., 2013), apparently a trait inherited by hybrid (2). This adaptation is well suited to deserts, but not to growth expectations in nursery production and urban landscapes. Abundant root-zone water often promotes root pathogens and mortality of such species (Mee et al., 2003). Genetic variation among the hybrid plants (Figs. 1 and 2) likely underlies the variability in hybrid $\mathrm{P}_{\mathrm{n}}$ and $g_{\mathrm{S}}$. Hybrid (1) gas exchange response, substantially greater than that either parent (Fig. 6A and B), is echoed by the results of Rieger et al. (2003), who found greater $P_{n}$ in the hybrid between Prunus ferganesis and $P$. persica than either parents.
Collectively, our data provide a first genetic, morphological, and physiological assessment of the landscape potential to the hybrid $S$. rotundifolia $\times S$. argentea in the context of the wildland parents (Sriladda et al., 2014). While AFLP genetics within each taxon were heterogeneous, the hybrids expressed traits clearly intermediate between genetic variability of the two parents. Genetic heterogeneity among the hybrids was not manifested in leaf morphology differences. Hybrid plants appeared to uniformly conserve aesthetically desirable leaf shape and color from the male parent, $S$. rotundifolia. However, gas exchange responses among the hybrid plants were considerably more variable. Greater hybrid (1) $P_{n}$ and $g_{\mathrm{S}}$ than either parent may suggest it conserved faster growth rate and greater tolerance of wet soil from $S$. argentea. While hybrid crown form is not yet definitively discernable, preliminary observation in 2015 suggests rapid growth and a distinctly wide pyramidal shape up to $1.5 \mathrm{~m}$ high. Conversely, low photosynthesis in the surviving hybrid (2) was expressed in slow growth on par with $S$. rotundifolia, and a more rounded crown form $\approx 0.5 \mathrm{~m}$ high. We have readily propagated softwood cuttings from the two surviving hybrid offspring for future development for low-water landscaping. 


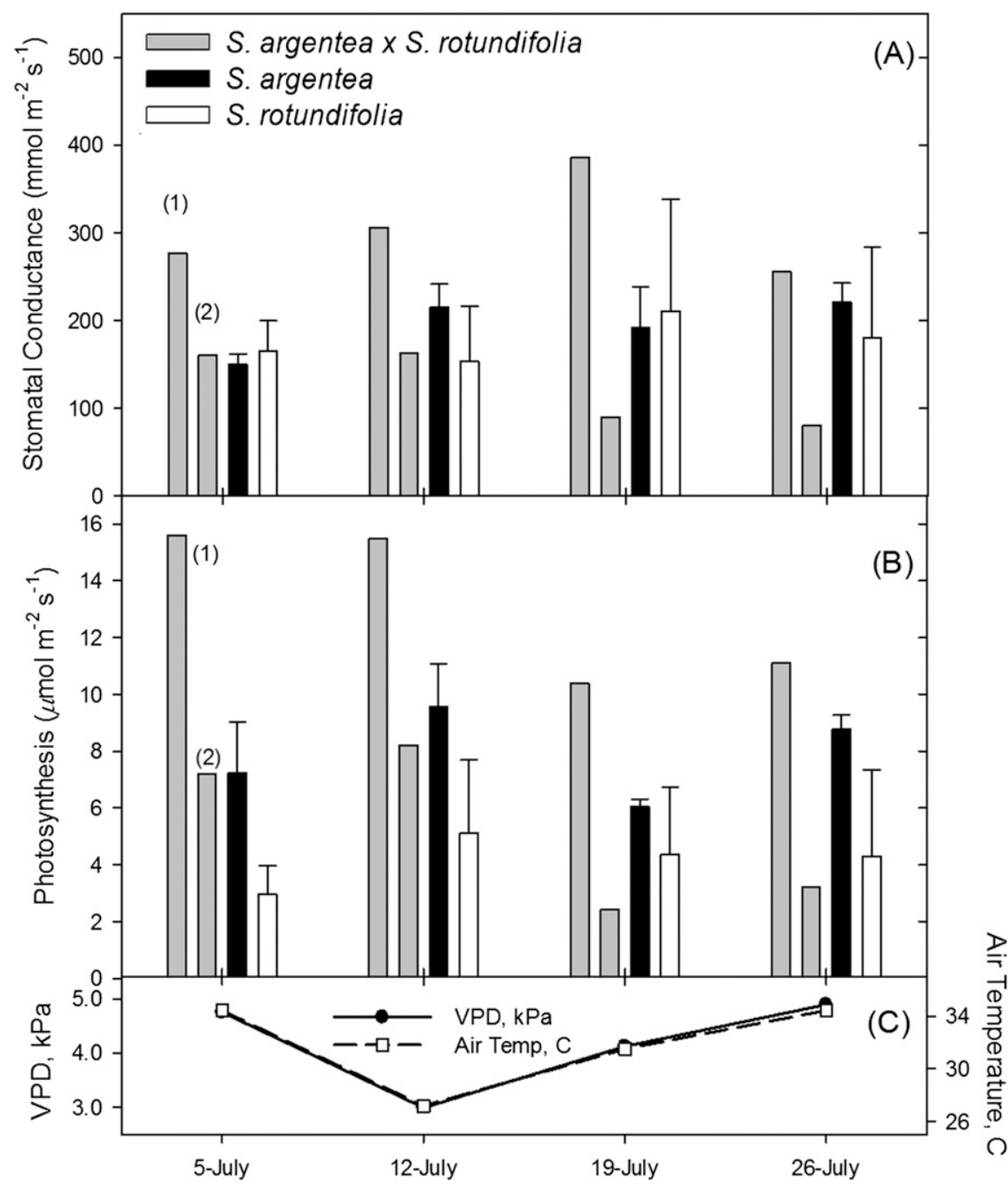

Fig. 6. Midday physiological responses of Shepherdia rotundifolia and Shepherdia argentea and the interspecific hybrid $S$. rotundifolia $\times$ argentea: $(\mathbf{A})$ midday stomatal conductance $\left(g_{\mathrm{S}}\right)$ and $(\mathbf{B})$ midday photosynthesis $\left(\mathrm{P}_{\mathrm{n}}\right)$. Bars labeled with (1) and (2) indicate responses of the single hybrid plants, and $S$. rotundifolia and $S$. argentea responses include SD $(\mathrm{n}=3)$. C is the maximum daily air temperature and vapor pressure deficit on each day of measurement.

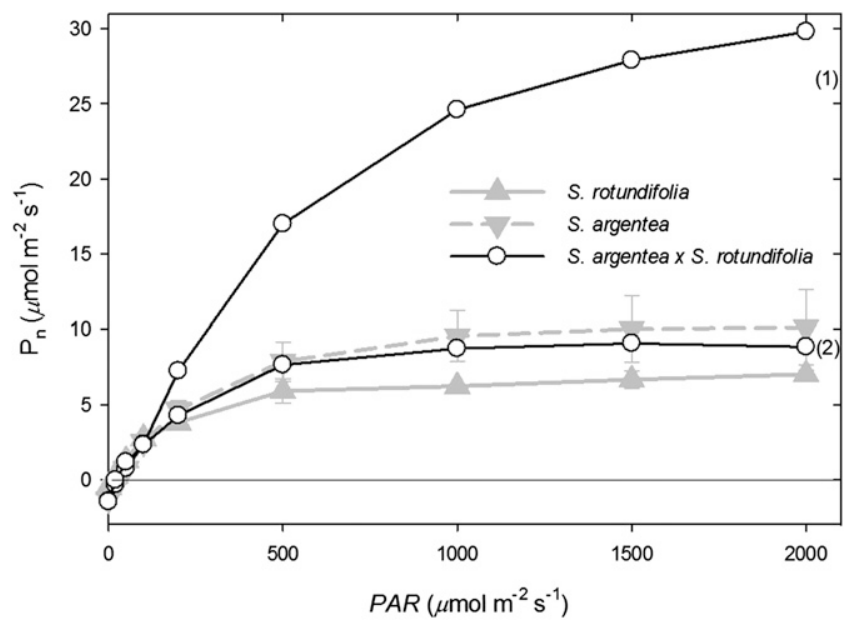

Fig. 7. Photosynthetic light response curve for Shepherdia rotundifolia and Shepherdia argentea and the interspecific hybrid $S$. rotundifolia $\times$ argentea. Bars labeled with (1) and (2) indicate responses of the single hybrid plants, and $S$. rotundifolia and $S$. argentea responses include SD $(\mathrm{n}=3)$.

Further study of hybrid drought and wet soil tolerance mechanisms is particularly warranted. Encouragingly for future development, cuttings from both hybrids to date appear more tolerant of wetter and more fertile root-zone conditions than the $S$. rotundifolia parent.
Nomenclature. We anticipate this hybrid and its derivatives will be sold commercially in the IMW. For the convenience, we are naming it as a hybrid species:

- Shepherdia $\times$ utahensis, Sriladda-KratschKjelgren, nothosp. Nova, Shepherdia argentea (Pursh) Nutt. $\times S$. rotundifolia Parry. Holotype UTC00270921.

- Further, we name two cultivars: Shepherdia $\times$ utahensis "Torrey" and Shepherdia $\times$ utahensis "Torrey Compact" for hybrids (1) and (2), respectively.

- Shepherdia $\times$ utahensis differs at the leaf level from the female parent Shepherdia argentea by having wider, revolute leaves, and from the male parent by having narrower-longer leaves with peltate rather than stellate abaxial trichomes.

\section{Literature Cited}

Beddes, T. and H.A. Kratsch. 2009. Seed germination of Roundleaf buffaloberry (Shepherdia rotundifolia) and Silver buffaloberry (Shepherdia argentea) in three substrates. J. Environ. Hort. 27:129-133.

Chen, J., J. Qin, K. He, and Z. Wang. 2009. Influences of water-stress on Shepherdia argentea seedlings growth and photosynthetic gas-exchange parameters. Acta Bot. Boreali-Occidentalia Sinica. 29:1649-1655

Dice, L.R. 1945. Measures of the amount of ecologic association between species. Ecology 26:297302.

Edmondson, J.L., Z.G. Davies, S.A. McCormack, K.J. Gaston, and J.R. Leake. 2011. Are soils in urban ecosystems compacted? A citywide analysis. Biol. Lett. 7:771-774.

Falush, D., M. Stephens, and K. Pritchard. 2007. Inference of population structure using multilocus genotype data: Dominant markers and null alleles. Mol. Ecol. 7:574-578.

Franks, P.J., P.L. Drake, and R.H. Froend. 2007. Anisohydric but isohydrodynamic: Seasonally constant plant water potential gradient explained by a stomatal control mechanism incorporating variable plant hydraulic conductance. Plant Cell Environ. 30:19-30.

Jakesova, H., J. Repkova, D. Hampel, L. Cechova, and J. Hofbauer. 2011. Variation of morphological and agronomic traits in hybrids of Trifolium pratense $\mathrm{x}$ T. medium and a comparison with the parental species. Czech J. Genet. Plant Breed. 47:28-36.

Johnston, J.A., L.A. Donovan, and M.L. Arnold 2004. Novel phenotypes among early generation hybrids of two Louisiana iris species: Flooding experiments. J. Ecol. 92:967-976.

Jun, J.H., J.H. Kwon, and K.H. Chung. 2009. Morphological characteristics of interspecific hybrids between Japanese plum (Prunus salicina Lindl.) cv. Soldam and Apricot (P. armeniaca L.) cv. Harcot. Korean J. Hort. Sci. Technol. 27: 269-274.

Karabourniotis, G., A. Kyparissis, and Y. Manetas. 1993. Leaf hairs of Olea europeae protect underlying tissues against ultraviolet-B radiation damage. Environ. Expt. Bot. 33:341-345.

Kjelgren, R., L. Rupp, and D. Kilgren. 2000. Water conservation in urban landscapes. HortScience 35:1037-1040.

Kjelgren, R., L. Wang, and D. Joyce. 2009. Water deficit stress responses of three native Australian ornamental herbaceous wildflower species 
for water-wise landscapes. HortScience 44 : 1358-1365.

Kuhlman, L.C., B.L. Burson, P.E. Klein, R.R. Klein, D.M. Stelly, H.J. Price, and W.L. Rooney. 2008. Genetic recombination in Sorghum bicolor $\mathrm{x} S$. macrospermum interspecific hybrids. Genome 51:749-756.

Mee, W., J. Barnes, R. Kjelgren, R. Sutton, T. Cerny, and C. Johnson. 2003. Water wise: Native plants for Intermountain landscapes. Utah State University Press, Logan, UT.

Meyer, S.E., R.K. Kjelgren, D.G. Morrison, W.A. Varga, and B. Schultz. 2009. Landscaping on the new frontier: Waterwise design for the Intermountain West. Utah State University Press, Logan, UT.

Monaco, T.A., D.A. Johnson, and J.E. Creech. 2005. Morphological and physiological responses of the invasive weed Isatis tinctoria to contrasting light, soil-nitrogen and water. Weed Res. 45:460-466.

Nelson, A. 1935. Rocky mountain herbarium studies III: The Elaeagnaceae - a mono-generic family. Amer. J. Bot. 22:681-683.

Newingham, B.A., C.H. Vanier, T.N. Charlet, K. Ogle, S.D. Smith, and R. Nowak. 2013. No cumulative effect of 10 years of elevated [CO 2] on perennial plant biomass components in the Mojave Desert. Glob. Change Biol. 19:2168-2181.

Press, M. 1999. Research review: The functional significance of leaf structure: A search for generalizations. New Phytol. 143:213-219.

Pritchard, J.K., M. Stephens, and P. Donnelly. 2000 . Interference of population structure us- ing multilocus genotype data. Genetics 155: 945-959.

Richer, C., J.A. Rioux, and M.P. Lamy. 2003. Tolerance evaluation of six indigenous or naturalized species under different northeastern Canadian climatic conditions. Can. J. Plant Sci. 83:825-833.

Rieger, M., R.L. Bianco, and W.R. Okie. 2003. Responses of Prunus ferganensis, Prunus persica and two interspecific hybrids to moderate drought stress. Tree Physiol. 23:51-58.

Rohlf, F.J. 1993. NTSYS-pc. Numerical taxonomy and multivariate analysis system (version 2.02). Exeter Publisher Ltd., Setauket, NY.

Scascitelli, M., M. Cognet, and K.L. Adams. 2010. An interspecific plant hybrid shows novel changes in parental splice forms of genes for splicing factors. Genet. 184:975-983.

Schwinning, S., B.I. Starr, and J.R. Ehleringer. 2005. Summer and winter drought in a cold desert ecosystem (Colorado Plateau) Part II: Effects on plant carbon assimilation and growth. J. Arid Environ. 61:61-78.

Soltis, P.S. and D.E. Soltis. 2009. The role of hybridization in plant speciation. Annu. Rev. Plant Biol. 60:561-588.

Sriladda, C., R. Kelgren, H. Kratsch, T. Monaco, S. Larson, and F.K. Shen. 2014. Ecological adaption of the endemic Shepherdia rotundifolia to conditions in its Colorado Plateau Range. West. N. Amer. Nat. 74:79-91.

Stelkens, R.B., C. Schmid, O. Selz, and L. Seehausen 2009. Phenotypic novelty in experimental hybrids is predicted by the genetic distance between species of cichlid fish. BMC Evol. Biol. 9:283-295.

St. Hilaire, R., M.A. Arnold, D.C. Wilkerson, D.A. Devitt, B.H. Hurd, B.J. Lesikar, V.I. Lohr, C.A Martin, G.V. McDonald, R.L. Morris, D.R. Pittenger, D.A. Shaw, and D.F. Zoldoske. 2008. Efficient water use in residential urban landscapes. HortScience 43:2081-2092.

Sun, C., F. Chen, N. Teng, Z. Liu, W. Fang, and X. Hou. 2010. Interspecific hybrids between Chrysanthemum grandiflorum (Ramat.) Kitamura and C. indicum (L.) Des Moul. and their drought tolerance evaluation. Euphytica 174: 51-60.

United States Department of Agriculture (USDA). 2012. Plants profile. Natural Resources Conservation Service. 4 Apr. 2012. 6 Jan. 2016. <http:// www.plants.usda.gov/java/profile?symbol=SHRO $>$.

Vereecken, N.J., S. Cozzolino, and F.P. Schiestl. 2010. Hybrid floral scent novelty drives pollinator shift in sexually deceptive orchids. BMC Evol. Biol. 10:1-12.

Vos, P., R. Hogers, M. Bleeker, M. Reijans, T. Van de Lee, M. Hornes, A. Frijters, L. Pot, J. Peleman, M. Kuiper, and M. Zabeau. 1995. AFLP: A new technique for DNA fingerprinting. Nucleic Acids Res. 23:4407-4414.

Yamada, T., T. Okuda, A. Makmom, A. Muhamad, and A. Furukawa. 2000. The leaf development process and its significance for reducing selfshading of a tropical pioneer tree species. Oecologia 125:476-482. 